\title{
The Effects of Using Summarization Strategies on Iranian EFL Learners' Reading Comprehension
}

\author{
Maryam Pakzadian \\ University of Isfahan, Iran \\ Maryam.pakzadian2011@gmail.com \\ Dr. Abbas Eslami Rasekh \\ University of Isfahan, Iran
}

Received: April 27, 2012

Accepted: May 28, 2012

Online Published: June 15, 2012

doi:10.5430/elr.v1n1p118

URL: http://dx.doi.org/10.5430/elr.v1n1p118

\begin{abstract}
It is already known that for being effective readers we need explicit strategy training and it is generally agreed that well-developed reading comprehension ability is the key to students' academic success .This comprehension ability is not a passive state which one possesses, but it is an active mental process which needs to be nurtured and improved. The study aims to explore the effectiveness of using summarization strategies makes any significant difference in EFL learners' level of comprehending English texts. It also aims to examine whether using summarization strategies at undergraduate level affect significantly the performance of male and female students' comprehension of texts. The data for this study were collected through two comprehension tests and a personal questionnaire from 40 English students who study at one of Payam Noor University branches in Isfahan. The data were analyzed descriptively and also inferentially. The overall findings of the study which enjoys pretest-posttest design indicated that after receiving summarization strategies training participants outperformed in posttest and there was not a significant difference between performance of female and male participants. The findings of the present study would help teachers and teacher trainers to construct and implement summarization strategies in EFL classes more effectively.
\end{abstract}

Keywords: Summarization strategies, Reading comprehension, Reading strategies, EFL Undergraduates

\section{Introduction}

Reading is the most frequently mentioned academic subject in which students with learning disabilities experience failure (Lindsey \& Kerlin, 1979). Students with learning disabilities have often been characterized as "inactive learners" who fail to select, implement, and monitor effective learning strategies spontaneously (Torgesen, 1982).Reading comprehension on the other hand involves a complicated combination of skills in which students utilize their understanding of various elements, the how of finding main ideas and details and make a distinction between the two. Some might suppose that summarization as a kind of reading strategies would be an effective strategy to smooth the progress of the cognitive process of comprehension. Summarization is an effective learning strategy that can help students to construct and retain a succinct summary of important propositions from text. Kintsch and van Dijk (1978) hypothesized that during the process of comprehension, readers form a macrostructure, or gist, from the microstructure (i.e., the semantic content of sentences in the text). Although some information may be recalled explicitly, it is the text's macrostructure that a reader primarily remembers and uses as a cue to recall other information from the text. Many teachers are unwilling to teach their students how to write summaries. Some view it as boring to teach and tedious to grade, so they avoid both as far as possible. However, if teachers become aware of the numerous advantages for students, and of effective methods of teaching it, they might be persuaded to embrace summarization as a crucial skill that their students should practice as often as possible, as part of an integrated reading and writing program. As students encounter text in different areas, they need an approach to sort information, and they need to see how individuals with sufficient background knowledge identify important information and summarize. Asking students to read and summarize reading selections without the teacher describing and routinely modeling how to use an appropriate summarization strategy, especially of varying text length, content area, and complexity, will not improve 
the ability of students to summarize. However, since almost all learning in school requires a student condense and remember what has been read, summarization comprehension strategies are important to teach.

\section{Effect of Summarization strategies on Comprehension}

Summary writing exemplifies a mixture of reading and writing. Writing a summary of a text can help learners connect gist of ideas, process thoughts, rephrasing and restructuring them in their own words (Perin, 2002).Graham and Hebert (2010) investigated the reciprocal relationship between writing and reading to see whether writing activities have an impact on reading activities. They concluded that having students write about what they have read simply will improve their reading abilities. Research on teaching summarization is mostly based on Brown and Day (1983) and Kintsch and Van Dijk (1978) model of text comprehension. Three kinds of operations which take place during reading are taken into account by these models including: (1) the elements of meaning are integrated into a coherent whole; (2) the whole meaning of the text is compressed into its main idea; and (3) the gist is used to modify those elements which have previously been constructed and to have an effect on those yet to be constructed. In comprehension process learners before having a text- based summary, mentally summarize all the elements in to a gist.In many studies teaching students how to use summarization strategies considered to have significant impact on their comprehension (Armbruster, Anderson, \& Ostertag, 1987; Doctorow, Wittrock, \& Marks, 1978; Wittrock \& Alesandrini, 1990). Wittrock and his colleagues suggested that the process of generating summaries helps readers build relations among concepts contained in a text as well as link these concepts to prior knowledge. Other studies conclude that summarization can help readers to focus on gist information and therefore improve comprehension (Anderson \& Armbruster, 1984; Pearson \& Fielding, 1996). Others have suggested that summarization improves comprehension by promoting self testing during reading and apply strategies to remedy comprehension breakdowns (Anderson\& Thiede, 2003; Brown \& Day, 1983; Garner, 1982; Palinscar, 1986; Palinscar \& Brown, 1984; Paris \& Lindauer, 1982). Brown and Day 1983 and Day 1980 report that in their study they designed 2 versions of summarization instruction, one inductive and the other deductive. Instructions were delivered to 22 low incomes, minority high school, each over 32 - hour session; excluding pretest and posttest they observed no significant differences in summarization process and product between the two instructed groups. However the two groups were significantly different from control group in terms of summarization efficiency, and summarization rule use. So while many teachers think students do not need to explicit strategy training, research shows it will play a crucial role in turning the students into effective and critical readers. Students who are trained in summary writing know how to paraphrase ideas in their own words instead of simply copying them and in this way they will be better researchers in future. Research shows Summarization instruction had significant effects on students' performance in standardized tests of reading comprehension (Baumann, 1984; Bean \& Steenwyk, 1984; Taylor \& Beach, 1984). The reason for this could be metacognitive awareness that the students have during the act of summarization. They restructure the ideas of the texts and give the salient information prominence in their summaries. In this way they become more critical readers, they practice writing while reading, they work on punctuation a fragmentation, and after all they learn how to nourish their reading skill hand in hand with their writing skill. Through summarization students learn how to reread, verify, and activate prior knowledge (Brown, Day\& Jones, 1983). As far as it concerned with the know-how of teaching summarization strategy, there are at least two major approaches. One based on Kintsh and Van Dijik's (1978) which is based on macroprocesses and microprocesses involved in summary writing and the other based on theoretical model of Brown and Day (1983) which point to Three macrorules, i.e. mental operations on the source text, were involved: the deletion of minor propositions, the generalization of several propositions into a superset idea and the construction of a new proposition denoting a global fact about events described by several propositions. Three summary-specific operations were added: the copy of a part of the text, the lexical or syntactic transformation of a sentence without modifying its meaning (paraphrase) and the production of off-the-subject sentences. Kintsh(1990) in her paper reports that college students generalized the content more with poor macrostructure rather than with summarizing the texts with good macrostructure. Cordero-Ponce (2000) in their study randomly selected 64 intermediate college level learners of French as a foreign language. The divided their participants to experimental and control groups. The results revealed that summarization training was effective for L2 readers. Comparing the number of many studies which has done in summarization strategies instruction in L1, we need more studies in relation to this area in L2. The researcher conducted this study based on 2 null hypotheses.

The study intended to address the following research questions:

1) There is no statistically significant difference in the reading comprehension achievement of undergraduate students who received summarization strategies instruction as treatment and those did not. 
2) There is no statistically significant difference between male and female groups regarding their scores on reading comprehension test after treatment.

\section{Methodology}

\subsection{Participants}

Forty Iranian freshman university undergraduates were invited to contribute to this study. They were 20 male and 20 female EFL undergraduates, studying at Payam Noor University, Isfahan, Iran. The participants were aged between 18 and 24 and the average age for the group was 21 . Based on the data obtained by a personal questionnaire all the participants had passed the same courses prior to their participation in this study and due to the results of TOEFL proficiency test all enjoy low intermediate English proficiency. It's worth noting, that some of the entire subjects were dropped from the study due to their absence in some treatment sessions or incomplete data.

\subsection{Materials}

In this research, the researcher used two types of instruments: two tests and one questionnaire:

\subsubsection{The personal questionnaire}

Before the participants began completing the tests, they were given a personal questionnaire on their sex, age, term of study, and the courses they had passed prior to their participation in the present study .This questionnaire included 5 questions and the researcher used it to gather data about participants' demographic information. The questionnaire is presented in the Appendix 1.

\subsubsection{Language proficiency test (TOEFL)}

This test comprised of multiple-choice reading passage, vocabulary, and grammar sections. The main study's 40 participants were selected through proficiency test and personal questionnaire out of 60 undergraduate students of EFL.

\subsubsection{The reading comprehension test}

The test of reading comprehension was composed of 3 passages followed by multiple choice format reading comprehension tests. The three passages and their following questions were derived from Payam-e- Noor University reading packages for EFL Undergraduate students written by Dr. Mohammad Hassan Tahririan (see Appendix 2)

\subsection{Pilot Study}

Before giving the tests to the main participants of the study, they were piloted with a group of $30 \mathrm{EFL}$ undergraduates with similar characteristics as those of the main participants of the study. It took about 30 minutes for either test to finish. The Cronbach's alpha for reliability of the tests in the pilot study was estimated. The results indicated the reliability of 0.70 for reading comprehension test. This indicated that the instruments enjoyed high reliability estimate and were therefore appropriate for the purpose of the study. Based on the results of pilot study, some items of the test were modified to avoid confusion on the part of test taker. The piloting section indicated that the time necessary for taking the test was 30 minutes.

\subsection{Procedure}

In instructional phase first the teacher made an attempt to define concept of summarization strategy in theory and practice. She, as a model tries to initiate using this strategy while reminding merits of this strategy in being effective readers. Then she gave explicit instruction of summarization strategies. After this step, the students tried to practice what the teacher modeled before on different tasks and texts. After the entire teacher encouraged independent use of summarization strategy. Also, the teacher provided scaffolding until they became independent. Fourth, the students evaluated their own strategy use immediately after each practice session by checking the strategy they had used and monitoring their understanding. Fifth, to develop larger repertoire of strategies, the students were asked to apply this strategy to new tasks. The students follow the instructional phase during 1 month of their educational semester in their reading class. The participants take the comprehension test once as pretest before going through the instructional program and once after it as a posttest. The time interval between two administrations was enough for students not to take advantage of whether memory effect or test effect.

The data collection phase of the present study was conducted in January 2012. Prior to completing the tests, the participants were informed about the aims of the study and how they could contribute to the investigation. Further, before the participants began completing the tests they were given the personal questionnaire (see 3.2.1) on their sex, age, term of the study and the EFL courses they had passed. They were then ran given reading comprehension test (see 3.2.2) and were asked to complete the tests in 30 minutes. While the test takers were completing the tests, the 
researcher answered their questions (if any) in their native language, Persian. After collecting and analyzing the answer sheets and the questionnaires, the researcher dropped those participants who provided incomplete data.

\section{Results}

As soon as the study enjoys a pretest -post test design, the researcher used paired sample T-test in order to compare the performance of participants in pretest and posttest. (see Table 1)

Results of data analyses (T-test) in the Table 2 indicate that there is a statistically significant difference between students in reading comprehension performance before treatment (pretest) and after the instruction (posttest) $(t=4.23$; $\mathrm{p}<005)$.

Regarding gender variable as independent variable in this research, there was not a significant difference between males and females after summarization strategy was taught (posttest) $(t=0.37, p<005)$ as such difference existed between them before treatment $(t=0.29, \mathrm{p}<005)$. Therefore, the second hypothesis presented in this research was not rejected.

\section{Discussion}

The present paper aimed to investigate the effects of summarization strategies training on undergraduates' level of reading comprehension. The teacher in instructional program tried to introduce summarization strategy, initiate strategy use as a model, and encourage students to practice strategy use, receive feedback, and invite students to be independent strategy users and readers, monitor themselves, and be strategic and effective readers. Based on the comparison that the researcher made between performance of students in pretest and posttest, the researcher draws some conclusions. The results support the effectiveness of instructional program. The results revealed that instruction had significant impact on students' performance on post test. The results were compatible with previous studies (Brown \& Day, 1983; Kintsch and van Dijik, 1979). The results support the idea that summarization is important as a tool for improving comprehension (Pressley, 2000). Although it is good to know like any other treatment, short time use of the instructional strategy training will not have that many long lasting and enduring effects on students' performance, in order to be efficient readers in long term academic setting, strategy use should be permanent, independent, and automatic. Some researchers claim that students outperform in post test after receiving summarization strategy training because while summarizing they pay more attention to the text. (Wilnogard \& Bridge ,1986). Like any other activity motivation plays a crucial role in producing summaries. Overall, the data show that undergraduate students can reliably implement and utilize summary strategies and that students and teachers view them positively. Most importantly, these data support the growing body of theoretical and empirical work focusing on the importance of reading-writing connections. However, a number of questions about generalization and maintenance remain unanswered. Further research will be necessary to determine the features of the summary skills strategy that are necessary to produce generalization and maintenance of effects, the length of time students will continue to use the summarization skills, and the factors that affect students' use of the summarization Strategies.

\section{Implications for Teaching}

The results approve the idea that explicit strategy training, here summarization strategies, result in higher reading ability in EFL classrooms. It is already known that in academic setting the most important skill for students is reading and helping students to be independent and critical readers is crucial. At the first steps teacher provides students with direct and deductive strategy training, modeling and scaffolding the procedure, but at later stages the teacher encourages the students to be independent users of summarization strategies while reading the text. All in all of the studies in SLA research verify the fact that learners definitely take benefit from inductive and deductive strategy instruction. If we, as EFL teachers only focus on explicit teaching of strategies and having students practice under their control can not affect their reading abilities in long term but helping them to become strategic and independent readers help them be effective readers on their own.

\section{References}

Anderson, T.H., \& Armbruster, B.B. (1984). Content area textbooks. In R.C. Anderson, J. Osborn, \& R.J. Tierney (Eds.), Learning to read in American schools (pp. 193-224). Hillsdale, NJ: Erlbaum.

Armbruster,B.B., Anderson, T.H., \& Ostertag, J. (1987). Does text structure / summarization instruction facilitate learning from expository text?Reading Research Quarterly, 22(3),331- 346. http://dx.doi.org/10.2307/747972

Bean, T.W., \& Steenwyk, F. (1984). The effect of three forms of summarization on sixth graders' summary writing and comprehension. Journal of Reading Behavior, 16, 297-307. 
Brown, A., Day, J., Jones, R. (1983). The development of plans for summarizing texts. Child Development, 54(4), 968-979. http://dx.doi.org/10.2307/1129901

Brown, A. L., \& Day, J. D. (1983). Macro-rules for summarizing texts: The development of expertise. Journal of Verbal Learning and Verbal Behavior, 22, 1-14. http://dx.doi.org/10.1016/S0022-5371(83)80002-4

Cordero-Ponce, W.L. (2000). Summarization instruction: effects of foreign language comprehensionand summarization of expository texts. Reading Research and Instruction, 29(4), 329-350. http://dx.doi.org/10.1080/19388070009558329

Day, J.D. (1980). Teaching summarization skills: A comparison of training methods. Unpublished doctoral dissertation, University of Illinois, Urbana.

Doctorow, M. J., Wittrock, M. C., \& Marks, C. B. (1978). Generative processes in reading comprehension. Journal of Educational Psychology, 70, 109-118. http://dx.doi.org/10.1037/0022-0663.70.2.109

Garner, R. (1982). Efficient text summarization - costs and benefits. Journal of Educational Research,75, 275-279.

Graham, S., \& Hebert, M. A. (2010). Writing to read: Evidence for how writing can improve reading. A Carnegie Corporation Time to Act Report. Washington, DC: Alliance for Excellent Education.

Kintsch, E. (1990). Macroprocesses and microprocesses in the development of summarization skill. Cognition and Instruction, 7 (3), 161-195. http://dx.doi.org/10.1207/s1532690xci0703_1

Kintsch, W., \& van Dijk, T.A. (1978). Toward a model of text comprehension and production. Psychological Review, 85(5), 363-394. http://dx.doi.org/10.1037/0033-295X.85.5.363

Lindsey, J. D., and Kerlin, M. (1979). Learning disabilities and reading disorders: A brief review of the secondary level literature. Journal of Learning Disabilities, 12, 408-415. http://dx.doi.org/10.1177/002221947901200611

Palinscar, A. S. (1986). Metacognitive strategy instruction. Exceptional Children, 53,118-124.

Palinscar, A. S., \& Brown, A. L. (1984). Reciprocal teaching of comprehension-fostering and comprehensionmonitoring activities. Cognition and Instruction, 1, 117-175. http://dx.doi.org/10.1207/s1532690xci0102_1

Paris, S. G., \& Lindauer, B. K. (1982). The development of cognitive skills during childhood. In B. R.

Wolman (Ed.), The handbook of developmental psychology, (pp. 333-349). Englewood Cliffs: Prentice Hall.

Pearson, P. D., \& Fielding, L. (1991).Comprehension instruction. In R.Barr, M.L. Kamil, P. Mosenthal,\& P.D. Pearson (Eds.), Handbook of Reading Research, 2, (pp. 815-860). White Plains, NY: Longman.

Pressley, M. (2002). Comprehension strategies instruction: A turn-of-the-century status report. In C.C. Block \& M. Pressley (Eds.), Comprehension instruction: Research-based best practices (pp. 11-27). New York: Guilford.

Thririan, M. (1996). Developing Reading Proficiency I. Tehran, Payam-e-Noor University Press.

Wittrock, M. C., \& Alesandrini, K. (1990). Generation ofsummaries and analogies and analytic and holistic abilities. American Educational Research Journal, 27, 489-502.

Table 1. Paired sample statistics for all subjects $(\mathrm{N}=40)$

\begin{tabular}{|l|c|c|c|c|c|}
\hline & $\mathbf{N}$ & Mean & SD & T & Sig \\
\hline Pre test & 40 & 12.525 & 2.32034 & -4.23 & .000 \\
\hline Post test & 40 & 13.175 & 1.97273 & & \\
\hline
\end{tabular}

Note $* \mathrm{p}<.0001 \quad * * \mathrm{p}<005$

Table A. comparison of pretest and posttest scores for gender variable

\begin{tabular}{|l|c|c|c|c|c|c|}
\hline & & $\mathbf{N}$ & Mean & SD & T & Sig \\
\hline Pre test & Female & 20 & 12.65 & 2.3681 & -0.29 & .331 \\
\hline & Male & 20 & 12.4 & 2.32605 & & \\
\hline Post test & Female & 20 & 13.1 & 2.14966 & -0.37 & 0.356 \\
\hline & Male & 20 & 12.85 & 2.18307 & & \\
\hline
\end{tabular}




\section{Appendix 1}

Please answer the following questions:

1. Your sex: Female/ Male

2. Your age...

3. Your term of study...

4. Your major (English translation/ English literature/teaching English)

5. EFL courses you had passes in university prior to your participation in this study...

\section{Appendix 2}

\section{Passage 1}

In ancient societies, most women married and began raising children soon after reaching puberty. They remained at home, received no formal education, and had little economic or social power. Exceptions included the women of ancient Egypt and Sparta. Both Egyptian and Spartan women could own and inherit property. In addition, Egyptian women could work outside the home, and Spartan women could receive a formal education.

1. In ancient societies, most women...

a. Could not receive education

b. c. owned and inherited property

c. Worked outside home

d. d. never married

2. Most ancient women...

a. Had no social or economic roles

b. c. were educated before they married

c. Had a lot of children

d. d. married several times

3. According to the passage, Egyptian and Spartan women...

a. Were good examples of ancient women

b. c. had exceptional advantages

c. Were responsible for their education.

d. d. had no economic or social power

4. It is implied that ancient children ...

a. Could not own property

b. c. were raised after puberty

c. Remained at home

d. d. had young mothers

5. Which of the following has not been mentioned as an advantage about ancient women?

a. Remaining at home

b. c. working outside home

c. Inheriting property

d. d. receiving education 


\section{Passage 2}

People commit crimes for various reasons. For example, many persons steal things they could not obtain otherwise. Others, such as drug addicts, steal to get money to by narcotics or other things they need. Some shoplifters steal for excitement, but others do so to stretch the family budget. Many automobile thieves take cars for joy-riding, but others strip down the stolen autos and sell them. Many embezzlers take money from their employers to meet a personal emergency, intending to return the money. The motives also vary in crimes of violence. A robber may kill his victim to avoid detection. Some gangsters torture people to obtain money. A man may beat his wife in a fit of a rage during a quarrel.

1. According to the passage, some people who steal money...

a. Don't need it

b. c. are shoplifters

c. Are criminals

d. d. love money

2. We understand from the passage that...

a. Drug addicts are the most dangerous criminals

b. Detectors may kill robbers

c. There are many criminals in the world

d. There are many reasons why a person commits a crime

3. Which of the following has not been mentioned as a crime?

a. Beating wives

b. Making money

c. Killing victims

d. Stealing cars

4. According to the passage which of the following is a crime?

a. Returning money

b. Stretching the family budget

c. Stealing things

d. Joy-riding

5. The main idea of this passage is related to ...

a. Stealing things

b. Torturing people

c. Causes of crime

d. Buying narcotics 


\section{Passage 3}

The earliest recorded evidence of religious activity dates from only about 60,000 BC. However, anthropologists and historians of religion believe that some form of religion has been practiced since people first appeared on the earth about two and a half million years ago. Experts think prehistoric religion arose out of fear and wonder about natural events, such as the occurrence of storms and earthquakes and the birth of babies and animals. To explain why someone died, people credited supernatural powers greater than themselves or greater than the world around them.

1. The passage is mainly about...

a. Anthropology and religion

b. The origin of religion

c. Religious people and places

d. Different kinds of religion

2. We understand from the passage that religion

a. Is not a recent phenomenon

b. Has been practiced since $60,000 \mathrm{BC}$

c. Was practiced even before man appeared on earth

d. Has been mentioned in history

3. According to the passage, prehistoric people...

a. Believed in fear and wonder

b. Believed in supernatural powers

c. Could control storms and earthquakes

d. Could explain why someone died

4. Which of the following has been suggested as the basis for prehistoric religions?

a. Evidence for historians

b. Fear about natural events

c. Love for children

d. Care for animals

5. According to the passage, religion beliefs relate to...

a. Powers greater than we can imagine

b. Natural powers used for social purposes

c. Supernatural powers mentioned in history

d. Powerful people in the history of mankind 